\title{
NTRK1 Gene Mutation-associated Hereditary Sensory and Autonomic Neuropathy
}

\author{
Richa Mishra ${ }^{1}$, Aditi Kapur ${ }^{2},{ }^{\oplus}$ Rakesh Pilania $^{3}$, Sarojini Rai ${ }^{4}$
}

\begin{abstract}
Rare diseases, however intriguing they may seem, are often a dilemma in terms of diagnosis and treatment planning, especially owing to scanty literature among various age-groups. Being presented is a case of a 10-month-old child with congenital insensitivity to pain, otherwise known as Hereditary Sensory Autoneuropathy (HSAN) Type 5. The child was reported with Self-injurious Behavior (SIB), recurrent infections, corneal scarring, and spontaneous tooth mobilities. Upon a series of stepwise diagnostic workup, this was found to be a rare case of HSAN5. The genetic basis of the disorder was found to be a mutation in the NTRK1 gene, which is otherwise most commonly involved in HSAN4, however phenotypic features of the latter were not evident. Supportive treatment and counseling were key in providing care to the child.

Keywords: HSAN, Rare disease, SIB.

Journal of South Asian Association of Pediatric Dentistry (2021): 10.5005/jp-journals-10077-3088
\end{abstract}

\section{INTRODUCTION}

Congenital Insensitivity to Pain, otherwise known as Hereditary Sensory Autoneuropathy type 5 is a genetic disorder included in the spectrum of diseases called Hereditary Sensory Autonomic Neuropathy (HSAN), which are a set of unrelated conditions causing a lack of pain perception among other presenting symptoms. Pain-free joint destructions, spontaneous exfoliation of teeth, corneal injuries due to absent corneal reflexes, recurrent soft tissue infections, abscesses, and osteomyelitis are found to occur in these patients. ${ }^{1}$

\section{Case Description}

A 10 months old female child was brought to the Pediatric Dentistry Unit at our center, for evaluation of her tongue which had several splits along with whitish coating on its surface. This patient was referred from the Department of Pediatrics, where she was admitted for management of loose stools and fever. Parents also reported that such infections were frequently occurring in this child, requiring multiple hospital admissions. ${ }^{2,3}$

The patient was the first borne child of a non-consanguineous marriage. Intraoral examination revealed primary dentition stage, with the upper and lower central and lateral incisors present and lower molars in erupting stage. Heavy scrapable coatings were found on the tongue surface and the tongue had several longitudinal and transverse splits, which had caused dysmorphia of the tongue (Fig. 1). It was observed that the child had tonguebiting habit that was episodic in nature and was more frequent during night time. Parents also reported, breath-holding episodes. Differentials for Self-injurious Behavior (SIB) like Lesch Nyhan, de Lange syndrome, Rett's syndrome, Moebius syndrome, and Gilles de la Tourette syndrome were considered.

Investigations, done as part of routine examination at the department of Paediatrics did not reveal hypokalemia and uric acid levels were normal, thereby helping to rule out Lesch Nyhan syndrome. Clinical features of the other above-mentioned syndromes were not present in the child. A scraping of the tongue was also collected because of the possibility of candida infection.

\footnotetext{
1-4Pediatric and Preventive Dentistry, Oral Health Sciences Centre, PGIMER, Chandigarh, India

Corresponding Author: Aditi Kapur, Pediatric and Preventive Dentistry, PGIMER, Chandigarh. Phone: +91 9815966348, e-mail: draditikmalhotra@gmail.com

How to cite this article: Mishra R, Kapur A, Pilania R, et al. NTRK1 Gene Mutation-associated Hereditary Sensory and Autonomic Neuropathy. J South Asian Assoc Pediatr Dent 2021;4(3):190-192.

Source of support: Nil

Conflict of interest: None
}

Rounding off the cusps and incisal edges of all the teeth were done in the usual lap to lap position. Oral hygiene instructions, with emphasis on tongue cleaning were provided. Based on the findings of inability of pain perception, thereby causing self-inflicted injuries, a provisional diagnosis of Congenital insensitivity to pain was made. Mild papillary hypertrophy and recurrent infections also pointed towards the spectrum of HSAN. Anhidrosis was not present in the child, which would have pointed towards the diagnosis of HSAN 4 (Congenital Insensitivity to Pain with Anhidrosis). As a part of work up, genetic testing was carried out which revealed a mutation in the NTRK 1 gene on the chromosome 1 encoding NGF $\beta$ (nerve growth factor beta). Based on these clinical and genetic findings, a diagnosis of HSAN5 was made. The patient's caregivers were counseled about the same. It was stressed that the child be kept under constant supervision at home in order to prevent further biting injuries and report for timely follow up examinations. A possibility of bite guard was not considered due to the severity of her biting habits and because of being a potential infectious agent and even a choking hazard. Genetic counseling was also advised.

During follow up at 18 months of age, parents reported severe biting of upper digits, causing considerable disfigurement (Fig. 2). Also, extraoral examination showed that the child had developed corneal opacity in the left eye. Intraoral examination showed erupted upper and lower canines, which were found to be the

(c) The Author(s). 2021 Open Access This article is distributed under the terms of the Creative Commons Attribution 4.0 International License (https://creativecommons. org/licenses/by-nc/4.0/), which permits unrestricted use, distribution, and non-commercial reproduction in any medium, provided you give appropriate credit to the original author(s) and the source, provide a link to the Creative Commons license, and indicate if changes were made. The Creative Commons Public Domain Dedication waiver (http://creativecommons.org/publicdomain/zero/1.0/) applies to the data made available in this article, unless otherwise stated. 

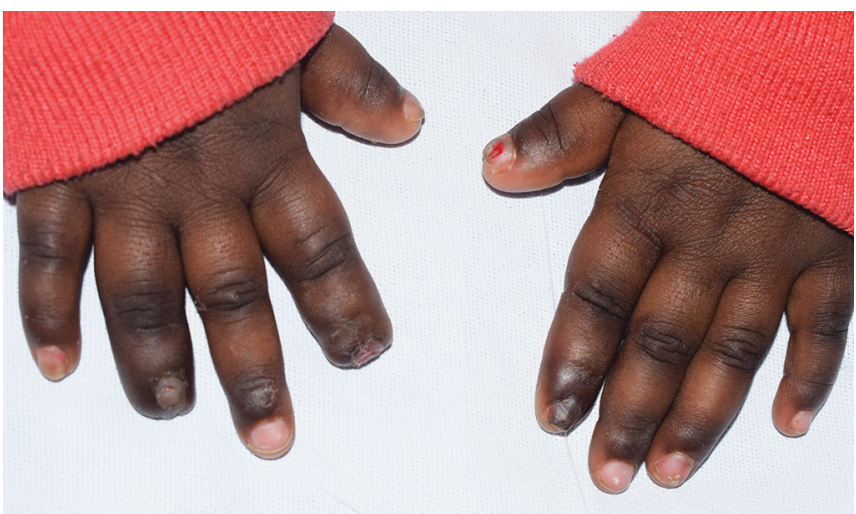

Fig. 1: Disfigurement of digits due to biting habit

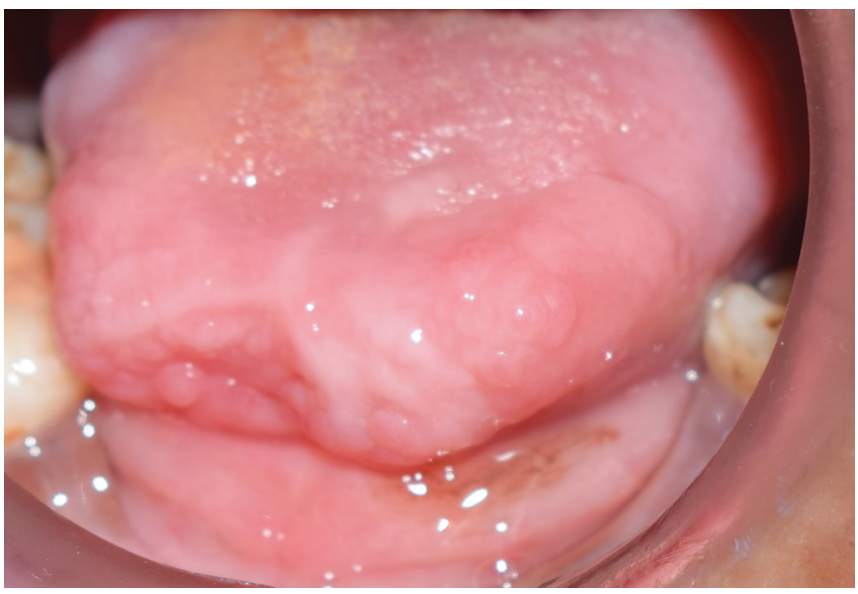

Fig. 2: Disfigurement of tongue due to biting habit, owing to lack of pain perception

teeth involved in this self-mutilative habit. Rounding off of these teeth was done as a part of conservative treatment approach.

Further at 19 months of age, the child was brought with a swelling in the left side of lower face (Fig. 3). Intraorally, sloughing was found and severe bone loss exposing the furcation of tooth 74 (Fig. 4), which had to be extracted. Thorough cleaning and debridement of the socket was done and pieces of bony sequestrum were removed. The developing 75 (primary left mandibular second molar) could be appreciated deep within the socket and was left undisturbed. The patient was kept on intravenous antibiotics subsequently. The tooth 75 , in Nolla's stage VI, had displaced markedly in the socket and had a lack of bone support and was extracted. Thorough cleaning and debridement were done and follow ups advised. A similar observation was made at 20 months of age when spontaneous extraction of 84 and 85 occurred. The patient was kept on monitoring and all the previous instructions were further reinforced.

The family was counseled regarding the further course the disease might take. Considering the age of the child and the disease progress, further treatment planning would involve the use of bite guards and dental prosthesis for the child.

\section{Discussion}

HSAN5 is an autosomal recessive disorder that was first reported by Jan Minde in the year 2004 in a large Swedish family. Several members of this family were reported to have a diminished perception of temperature caused by a point mutation of the gene

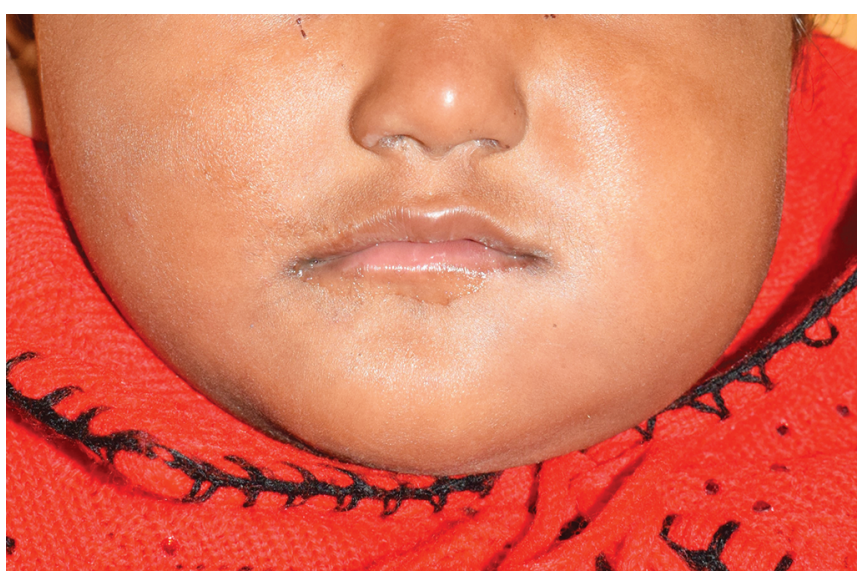

Fig. 3: Swelling with respect to unilateral lower face

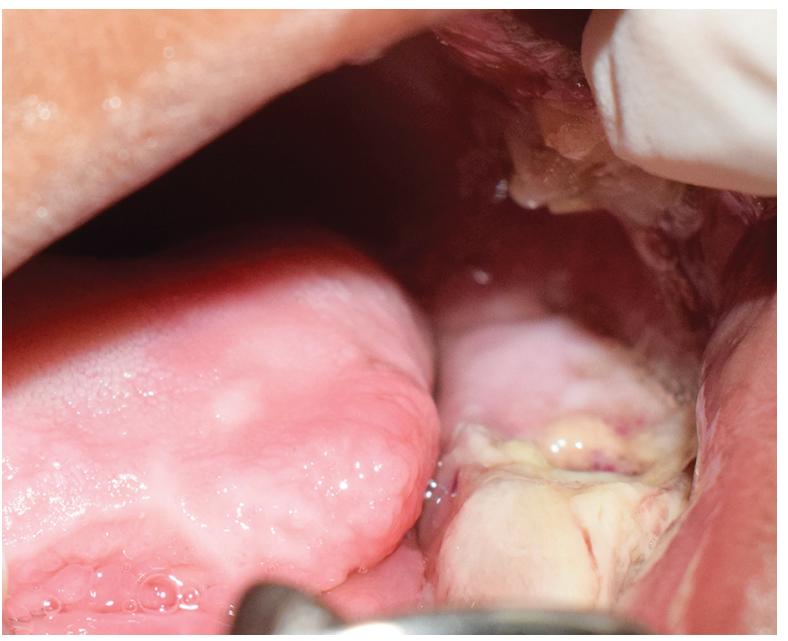

Fig. 4: Sloughing and bone loss with respect to tooth, 74

NGF $\beta$ causing a change from arginine to tryptophan at residue 100 in the mature NGF $\beta$ sequence $\left(\mathrm{NGF}^{\mathrm{R} 100 \mathrm{~W}}\right){ }^{4}$ The $\mathrm{NGF}^{\mathrm{R} 100 \mathrm{~W}}$ mutant fails to bind and stimulate the $75 \mathrm{kDa}$ neurotrophic factor receptor $\left(\mathrm{p} 75^{\mathrm{NTR}}\right)$ - mediated signaling cascades. This mutant, however retained the capability to activate TrkA receptor and downregulate signaling pathway for neuronal survival and differentiation, in a similar manner to the wild type of NGF $\beta .{ }^{4}$ However, the present case had a mutation in the NTRK1 gene. Phenotypically, the disorder did not have characteristics of HSAN4, where severe anhidrosis is found. Only two such case reports of NTRK1 mutation accompanied with phenotypic features of HSAN5 have been reported and the authors had suggested that HSAN type 4 and 5 should not be considered as distinct disorders. ${ }^{5,6}$ Houlden et al. in 2001 reported such a disorder in a 9 year old Pakistani boy with recurrent infections, joint fractures and partial anhidrosis. ${ }^{5}$ Carvahlo et al. in 2010 reported about six children, both male and female, in an Arab family with no pain and temperature sensation, anhidrosis and recurrent infections. ${ }^{6}$ It was hence noted that the spectrum of HSAN5 be increased to encompass the phenotypic findings of HSAN4. However, these reports did not mention the dental status of these children. Dental findings in HSAN5 were reported by Kalaskar and Kalaskar in the form of tongue biting and auto-extraction of deciduous teeth. However, the genetic findings were not mentioned. ${ }^{7}$ Dental findings along with genetic basis of the disease have been elaborated in the present case. 
Since the child with HSAN usually first presents with manifestations of SIB, other clinical conditions which lead to self-inflicted injuries, mentioned above, need to be ruled out. SIB forms a part of several neurodevelopmental and psychopathological disorders. Specific syndromes, with different molecular or genetic basis show different characteristics of SIB depending on etiology. Lesch-Nyhan syndrome, is an inherited disorder caused due to deficiency of an enzyme, hypoxanthine-guanine phosphoribosyl transferase-1 (HGPRT-1), produced by mutations in the HPRT gene on the X-chromosome and leads to hyperuricemia, neurological dysfunctions and cognitive and behavioral disturbances. ${ }^{8}$ Rett syndrome is a degenerative disorder characterized by intellectual disability, apraxia of gait, stereotyped motion of the hands, loss of facial expression, and a period of autistic-like withdrawal. Tourette syndrome is characterized by motor abnormalities and psychiatric problems such as most commonly obsessive-compulsive disorder (OCD) and attention deficit hyperactivity disorder (ADHD). ${ }^{9}$ Moebius syndrome is rare disease characterized by nonprogressive congenital VIth and VIIth cranial nerve palsy causing neurological and ophthalmological manifestations. ${ }^{10}$

Causes of recurrent infections, such as primaryimmunodeficiency disorders should also be considered. The various types of HSAN (1-9) present with slight variations in their clinical manifestations and genetic testing is required to reach a final diagnosis.

The diagnosis of such rare cases requires such close cooperation between the pedodontist and pediatrician, that delineation of roles between the two is not always possible as both are involved to the same extent in diagnosis of the case and providing symptomatic treatment according to the clinical presentations. The involvement of Pediatric Dentist throughout the process of diagnosis and treatment planning proves to be essential for management of HSAN and a thorough evaluation with a Pediatric Neurologist and Geneticist is required for reaching a definitive diagnosis. Since a child with HSAN presents with a myriad of symptoms, supportive treatment is provided by specialists in each field including those in Pediatrics, Ophthalmology, and Pediatric dentistry. The disease presents with several oral manifestations both as a course of the disease and associated SIB, hence, timely dental treatment is of utmost importance. Treatment plan should be as conservative as possible in order to preserve the deciduous teeth to aid in proper nutrition and growth of the young child. However, if aggressive bone loss sets in as in the present case, dental extractions are the only option. Considering the child's age and the risk of choking hazard, therapies involving restraint and bite guard may be planned to prevent further damage due to SIB.

Treatment of the disorder is supportive in nature and is best provided in a multidisciplinary manner. The primary caregivers need to be advised to monitor the child in order to avoid self-mutilation episodes. The child, therefore, should be under close monitoring and frequent follow ups. Genetic counseling of parents of such children is also an important aspect of providing care. Conservative management is always advisable in the beginning, but depending on the severity and anticipated damage, more radical approaches are always suitable in these cases.
This is a rare case wherein the differences in genetic findings and clinical manifestations between HSAN4 and 5 isn't quite well delineated. Such genetic disorders presenting with self-inflicted injuries allowing various pathways leading to SIB to be discovered. Detailed evaluation of such cases not only help us in adequate treatment planning but also gives us insight about the intricacies of neural function and pain pathways as well.

\section{Conclusion}

The importance of reporting this case lies in the fact that only two such reports exist in literature where the entities of HSAN4 and 5 appear to merge in genotypic and phenotypic features and none of the previous studies have described dental findings in such cases. The comprehensive understanding of such cases encompassing genetic, systemic, and dental findings will help in better facilitating management.

\section{ORCID ID}

Aditi Kapur ๑ http://orcid.org/0000-0002-6492-5868

\section{References}

1. Minde J, Toolanen G, Andersson T, et al. Familial insensitivity to pain (HSAN V) and a mutation in the NGFB gene. A neurophysiological and pathological study. Muscle Nerve 2004;30:752-760. DOI: 10.1002/ mus.20172.

2. Limeres J, Feijoo JF, Baluja F. Oral self-injury: an update [Internet] Dent Traumatol 2013 [cited 2020 Sep 29]. Available from: https:// pubmed.ncbi.nlm.nih.gov/22340154/https://doi.org/10.1111/j. 16009657.2012.01121.x

3. Tewari N, Mathur VP, Sardana D, et al. Lesch-Nyhan syndrome: the saga of metabolic abnormalities and self-injurious behavior. Intract Rare Dis Res 2017;6:65-68. DOI: 10.5582/irdr.2016.01076

4. Sung K, Ferrari LF, Yang W, et al. Swedish Nerve Growth Factor Mutation (NGFR100W) defines a role for TrkA and p75NTR in nociception. J Neurosci 2018;38:3394-3413. https://doi.org/10.1523/ JNEUROSCI.1686-17.2018

5. Houlden $\mathrm{H}$, King RH, Hashemi-Nejad A, et al. A novel TRK A (NTRK1) mutation associated with hereditary sensory and autonomic neuropathy type V. Ann Neurol 2001;49:521-525. https://doi. org/10.1002/ana.103

6. Carvalho OP, Thornton GK, Hertecant J, et al. A novel NGF mutation clarifies the molecular mechanism and extends the phenotypic spectrum of the HSAN5 neuropathy. J Med Genet 2011;48:131-135.

7. Kalaskar R, Kalaskar A. Hereditary sensory and autonomic neuropathy type V: Report of a rare case. Contemp Clin Dent 2015;6:103. DOI: 10.4103/0976-237X.149302

8. Mohapatra S, Sahoo AJ. Self-injurious Behavior in a Young Child with Lesch-Nyhan Syndrome. Indian J Psychol Med 2016;38:477-479. DOI: 10.4103/0253-7176.191389

9. Mathews CA, Waller J, Glidden D, et al. Self injurious behavior in Tourette syndrome: correlates with impulsivity and impulse control. J Neurol Neurosurg Psychiatry 2004;75:1149-1155. DOI: 10.1136/jnnp.2003.020693

10. Picciolini O, Porro M, Cattaneo E, et al. Moebius syndrome: clinical features, diagnosis, management and early intervention. Italian J Pediatr 2016;42:56. DOI: 10.1186/s13052-016-0256-5 